\title{
Chapter 5 \\ Interdependencies of Internal Migration, Urbanization, Poverty, and Inequality: The Case of Urban India
}

\author{
Edgar Wilson, Kankesu Jayanthakumaran, and Reetu Verma
}

Keywords Internal migration · Urbanization · Poverty · Inequality · Interdependencies $\cdot$ India

\section{Introduction ${ }^{1}$}

In India, the number of metropolitan cities with a population of around 1 million people and above has increased from 35 in 2001 to 53 in 2011. Around 43\% of the urban population resides in metropolitan cities. ${ }^{2}$ By 2030, the urban population of India is predicted to increase by a total of 163 million, relative to an increase in the rural population by 30.9 million (UN DESA 2014). Unplanned growth in the urban population tends to put pressure on regional/urban disparities and the rapidly increasing slum-dwelling population. In 2011-2012, the headcount ratio (HCR) based on \$ 1.90 (2011 PPP) per person per day for India is around 21.3\%, and the total number of people under this poverty line is 260 million. The urban Gini index increased by nearly 5 points from 34.3 to 39.1, and the urban mean log deviation (MLD) index increased by over 6 points from 19.3 to 25.5 during 1993-1994 to 2011-2012 (World Bank 2015a, b). The figures show a rapid increase in urban poverty and inequality.

Studies in India show some mixed results. Urbanization is a product of povertyinduced rural-urban migration, and it is due to urban pull and rural push (Datta 2006). Migration for employment from rural to urban areas emerges as a major tool for poverty alleviation (Kundu and Mohanan 2009). Urbanization has a systematic

\footnotetext{
${ }^{1}$ The views expressed in the study do not necessarily reflect those of the Government of India.

${ }^{2}$ Shrinivasan, R. and Chhapia, H. (2011), Delhi topples Mumbai as maximum city. The Times of India, India: Bennett, Coleman \& Co. Ltd. Retrieved 28 February 2017.

E. Wilson $\cdot$ K. Jayanthakumaran $(\bowtie) \cdot R$. Verma

School of Accounting, Economics and Finance, University of Wollongong,

Wollongong, NSW, Australia

e-mail: Kankesu@uow.edu.au
} 
and strong association with poverty reduction in neighbouring rural areas (Cali and Menon 2009). Urban to rural remittances appear to be particularly important in the well-being of the poorest states in India (Castaldo et al. 2012). The positive impacts of migration improved the status of migrants of both urban and rural households. However, these positive impacts come at a cost. The cost involves the risks of injury, exposure to disease, and long periods of separation from family (Deshingkar 2010). In general, despite the importance of the rate of urbanization and its link to urban poverty and urban inequality (Jack 2006; Satterthwaite 1997), it is surprising that existing research only pays attention to each dimension in isolation. ${ }^{3}$ Accommodating appropriate models to explain the link is challenging.

Thus, the objective of this paper is to systematically address the research gap between the dynamic links of internal migration, urbanization, and the poverty nexus in India. The remaining sections are organized as follows: Section 5.2 explores the trends and patterns of internal migration, urbanization, poverty, and inequality. Section 5.3 describes the methodology of stationarity testing and explains the data, followed by a cointegration time series analysis for a long period and a special state panel generalized method of moments (GMM) estimation at the state level. Section 5.4 discusses the results. Section 5.5 provides some conclusions related to the identified interdependencies.

\section{Trends and Patterns}

India shifted to a higher growth path trajectory in the 1990s based on the strength of its economic reforms in 1991 and the acceleration of further economic reforms in 2000s. Since the reforms, yearly growth was on average above 5\%. Economic reforms caused structural changes in the Indian economy: a slowing agricultural sector, a rising services sector, and increasing regional disparities. Growth in the agricultural sector has fallen from $24 \%$ in 2000 to $14 \%$ in 2012, while growth in the service sector has improved from $49 \%$ to $58 \%$. There was a slight increase in the manufacturing sector. Regional differences have also increased, for example, the per capita gross domestic product (GDP) ratio of the wealthy Indian state (Punjab) to the poor, populous state (Bihar) rose from nearly 3:1 in 1980 to over 4:1 in 2010.

Urbanization is also a consequence of the structural change from agriculture to the industrial and service sectors, which may be noted as the increased share of the national population residing in urban areas. Indian censuses indicate that urban population has increased by 91 million whereas urban population share has grown from $28 \%$ (286 million) in 2001 to $31 \%$ (377 million) in 2011. Rural population has increased by 90 million whereas rural population share has fallen from $72 \%$ (743 million) in 2001 to $69 \%$ (833 million) in 2011. This can be considered rapid

\footnotetext{
${ }^{3}$ For example, Carlsen (2000) shows some important empirical implications of the amenity and matching models and studies the regional pattern of migration, unemployment, and wages in Norway. The results confirm the matching model.
} 
urbanization, and the increase in urban population is due to the increase in natural growth rate, increase in in-migration, extension of city limits, and reclassification of areas from rural to urban. Urban migration from rural areas is an important component in determining urbanization. According to National Sample Survey (NSS) data (55th and 64th rounds), the number of rural-urban out-migrants increased by around 42 million (24\%) from 175 million in 1999-2000 to 217 million in 2007-2008. The presence of circular migration flows (the returning periodic urban to rural migration) makes it difficult to determine the actual statistics of migration.

Regardless of the aforementioned complications of migration, Fig. 5.1 shows the reality of actual net migration to urban areas. Positive net urban migration highly influences the overall urban population, although net migration has experienced considerable variation during the study period. Urban population growth in the 1970s stagnated in the 1980s and 1990s and then accelerated in the later part of the 1990s and early 2000s. Since the late 1990s, the urban population has experienced steady increases overall.

Rapid urbanization has consequences for urban poverty and income inequality. Hugo (2014) finds three possible linkages between urbanization and poverty: falling poverty rates in both rural and urban areas, significantly lower poverty rates in urban than in rural areas, and increasingly urban issues. For India, the pattern of change in the HCR and the increase in the slum-dwelling population indicate that poverty is becoming an increasingly urban issue. Applying the $\$ 1.90$ (2011 PPP) poverty line in India, poverty dropped from 410 million people in 1987 (HCR 50\%) to 260 million in 2011(HCR 21\%) (World Bank 2015a, b). Even though the HCR has fallen, the rate of decrease has been much slower in urban areas as compared to rural areas. In addition, the urban Gini index increased by around 5 points from 34 to 39 during 1990-2014, and the urban MLD index increased by around 7 points from 19 to 26

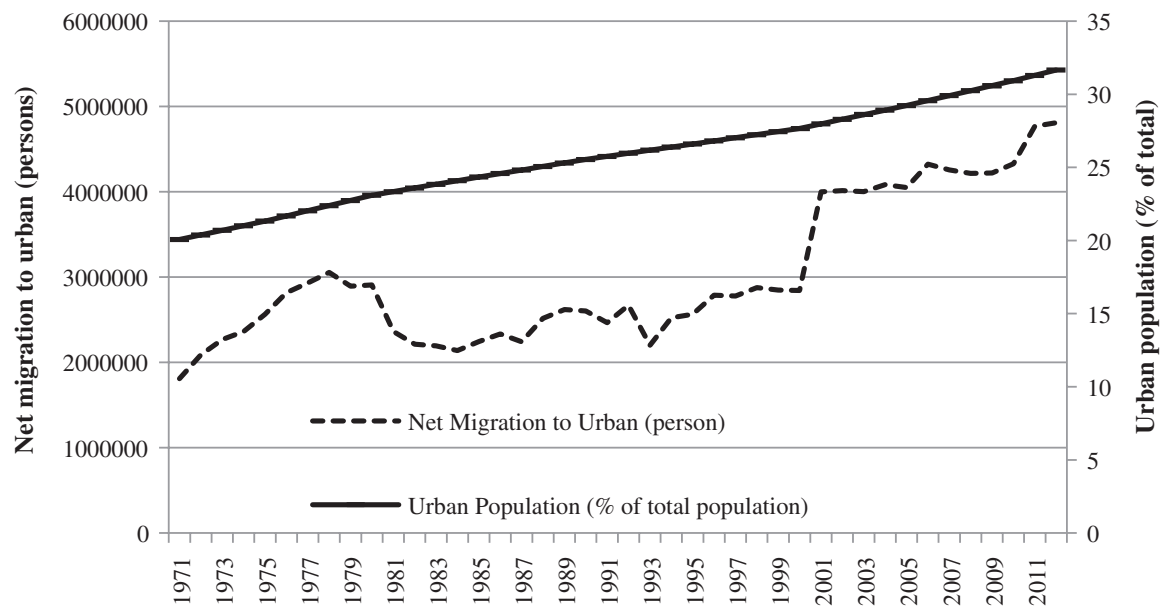

Fig. 5.1 Urban migration and population, 1971-2012. (Source: Urban population share of the total population [1971-2012] comes from World Development Indicators [World Bank 2014]. Net migration to urban areas is derived using authors' estimations) 


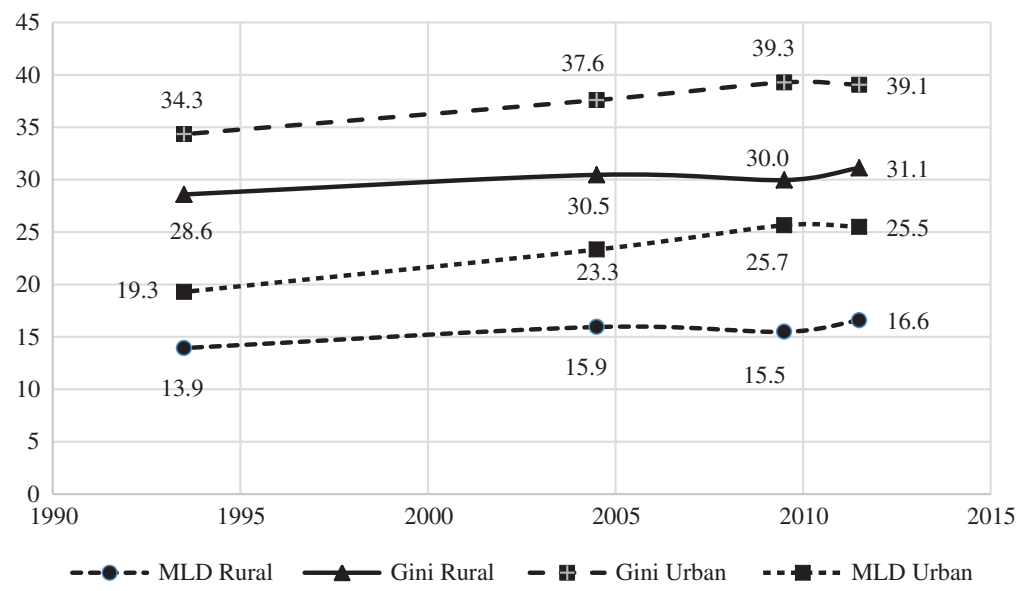

Fig. 5.2 India MLD and Gini index. (Source: World Bank (2015a, b) computed using PovcalNet)

(World Bank 2015a, b). These increases are much larger than the 2-3 percentage point increases in the two rural indices (Fig. 5.2).

The increasing number of slum-dwelling people is also an indication of urban poverty. The Indian census shows that the number of the urban population living in slums was around 65 million people in 2011 with a decadal growth of $25 \%$ from the 2001 census. ${ }^{4}$ Living in slums places social, economic, and financial burdens on households, and causes intergenerational poverty.

There are wide disparities across Indian states with regard to demographic and economic features. For example, Rajasthan, Madhya Pradesh, and Maharashtra are the biggest in land size; Uttar Pradesh, Maharashtra, Bihar, and West Bengal have the largest populations; Bihar, Uttar Pradesh, Madhya Pradesh, and Rajasthan have poor literacy rates; and Bihar, Orissa (Odisha), and Uttar Pradesh are relatively poor. Tamil Nadu, Maharashtra, and Gujarat are focusing on industries. Punjab and Haryana are still dependent on agriculture (for more details, see Cashin and Sahay 1996). Figure 5.3 shows the large variation across selected Indian states with regard to net migration to urban areas. The richest states (Tamil Nadu, Maharashtra, and Gujarat) have lower HCR and attract more migration to urban areas. In contrast, poorer states (such as Uttar Pradesh, Bihar, and Orissa) have higher HCR and net out-migration occurs as a result.

\footnotetext{
${ }^{4}$ In the census, the definition of slum-dwelling population is based on at least one of these characteristics: lack of access to water supply and sanitation, overcrowding, and using non-durable materials for dwellings.
} 


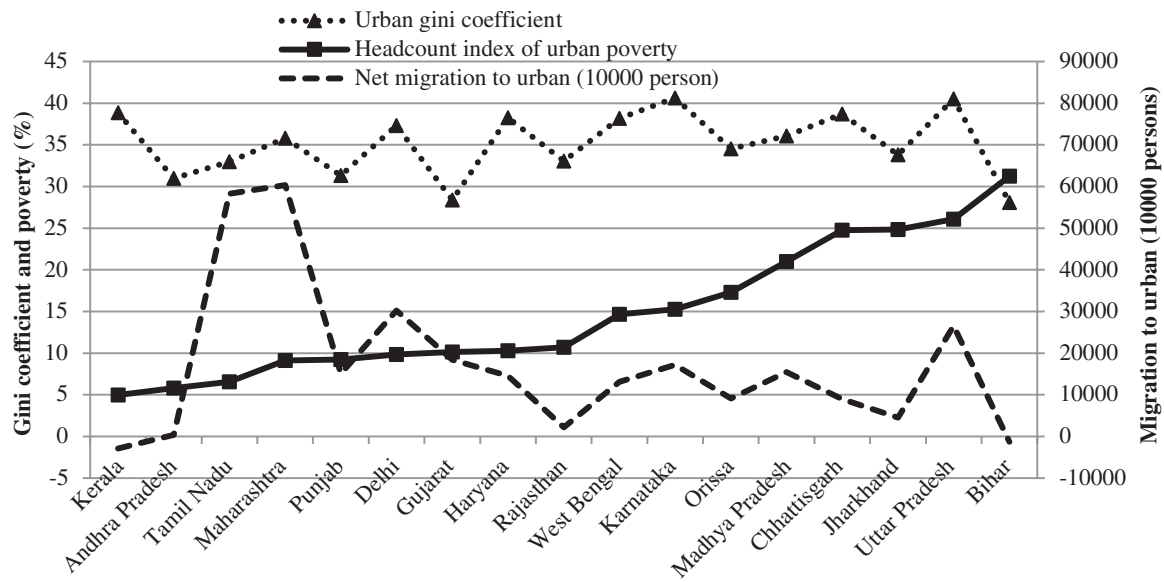

Fig. 5.3 State urban migration, Gini coefficient, and HCR of urban poverty: 2011. (Source: Ministry of Statistics NSS Report No. 533, Migration in India 2007-2008, National Sample Survey Office and Programme Implementation 2010). Note: The HCR of urban poverty is the estimate of the Tendulkar Committee for 2009-2010. This is based on the national poverty line (Planning Commission 2012)

The reduction in HCR of urban poverty in the last decade corresponds with an increase in numbers migrating to urban areas from 2000 onwards. However, during the same period, the Gini coefficient has increased drastically. Both affordability (demand side) and public spending on infrastructure (supply side) should go hand in hand to tackle disparity. In the absence of this, rapid urbanization has consequences on health conditions via the lack of hospital and healthcare facilities. Studies indicate that income polarization is highly associated with the unequal sharing of infrastructure (Bandyopadhyay 2011). In addition, rapid infrastructure development demands considerable energy use, and this may also be associated with environmental harm and can be linked to increasing poverty.

The dynamic and changing interdependencies between the available variables that represent health (infant mortality rate), education (gross enrollment ratio in primary school), and the environment (carbon emissions) can be seen in Fig. 5.4. The urban infant mortality rate has been decreasing at a fast pace, while the gross enrollment ratio in primary schools has increased over the 1971-2012 period. However, as expected, with rapid urbanization, carbon emissions have been increasing rapidly in India over the same period.

\section{Methodology}

To test for dynamic temporal interdependencies between the key variables, it is important to first determine the temporal properties of the data. The dynamic longrun cointegrating analysis will be followed up to show complex interdependencies 


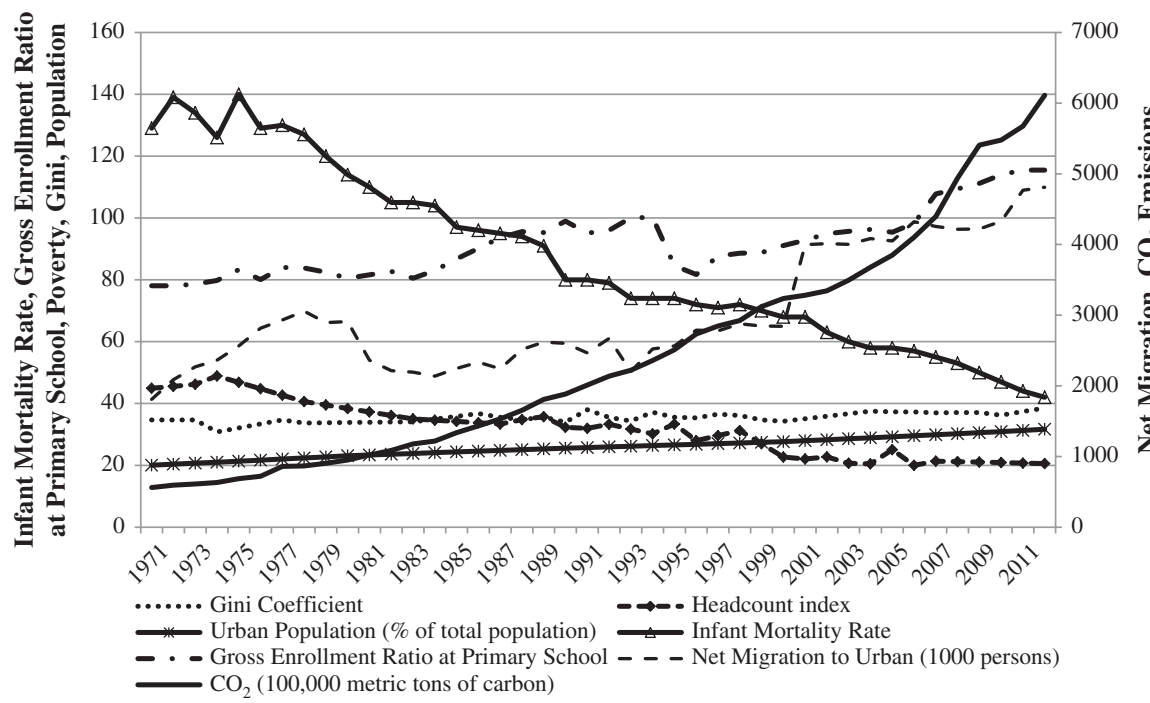

Fig. 5.4 Urban interdependencies, 1971-2012. (Source: World Bank 2015a, b)

and feedback at the national level over a long period. The spatial panel analysis calculates the respective elasticities at state level. A conclusion will be drawn using both analyses.

\subsection{Stationarity Tests}

The augmented Dickey-Fuller stationarity test is used to examine the unit roots of the time series. The results reported in Table 5.1 show that all variables in Naperian logs are nonstationary in their levels except the Gini coefficient measure of inequality. Differencing and testing show that all variables become stationary in the first differences with the exception of the urban population (which is possibly nonlinear or second difference stationary-this will be considered in subsequent estimations).

Based on these results, a cointegration estimation is required in order to avoid finding spurious relationships between the stochastic variables. We start with the autoregressive distributed lag (ARDL) cointegration approach and then consider the Johansen cointegration method. These procedures are limited to using national data, which are available for the years from 1971 to 2012. The procedures allow us to identify the long-run relationships between the variables (in addition to the observed trends) and determine long-run elasticities. The short-run (error correcting) deviations from these long-run relationships can be derived, providing the elasticities of the short-run dynamics. 
Table 5.1 Augmented Dickey-Fuller test

\begin{tabular}{|c|c|c|}
\hline & Intercept only & Intercept and trend \\
\hline \multicolumn{3}{|c|}{ Levels } \\
\hline$m$ & -0.529 & -1.524 \\
\hline$p$ & -0.595 & -2.874 \\
\hline$i e$ & -1.826 & $-4.584^{* * *}$ \\
\hline$u d$ & 0.224 & -3.050 \\
\hline co & -0.797 & -1.634 \\
\hline en & 1.550 & -1.375 \\
\hline im & 1.105 & -1.993 \\
\hline$e d$ & -0.824 & -2.313 \\
\hline \multicolumn{3}{|c|}{ First differences } \\
\hline$m$ & $-3.987^{* * *}$ & $-3.995^{* *}$ \\
\hline$p$ & $-6.953^{* * *}$ & $-6.852^{* * *}$ \\
\hline ie & $-6.606^{* * *}$ & $-6.579^{* * *}$ \\
\hline$u d$ & -1.757 & -1.164 \\
\hline co & $-4.409^{* * *}$ & $-4.497^{* * *}$ \\
\hline en & $-3.524^{* *}$ & $-3.689^{* * *}$ \\
\hline$i m$ & $-5.537^{* * *}$ & $-5.829^{* * *}$ \\
\hline$e d$ & $-5.453^{* * *}$ & $-5.441^{* * *}$ \\
\hline
\end{tabular}

Source: Authors' computations

Note: All variables are in Naperian logs; Definitions of the variables are in Sect. 3.5

*** significant at the $1 \%$ level; ${ }^{* *}$ significant at the $5 \%$ level; ${ }^{*}$ significant at the $10 \%$ level

This dynamic overview of the intertemporal interdependencies will then be complemented with the spatial panel estimation of GMM. The procedure will apply fixed effects to the state-level data and includes fixed effects for the more recent period 2006-2011. Each method will be subsequently considered.

\subsection{The ARDL Cointegration Approach}

To test for the long-run association between the chosen variables, this study adopts the ARDL approach proposed by Pesaran and Shin (1998) and Pesaran and Pesaran (1997, 2009). This method has four advantages. First, the ARDL can be used regardless of the order of integration while other cointegration techniques involve 
variables to be of equal degree of integration, thus avoiding the pretesting issues associated with the standard cointegration tests (Pesaran et al. 2001). Second, the ARDL is a statistically significant and robust approach for establishing cointegrating associations in small samples. The current study, though having a relatively small number of 42 annual observations, has a large sample size spanning over four decades, 1971-2012. Third, the ARDL applies the $F$-test, and this distinguishes which series is the dependent variable when cointegration occurs (Narayan and Narayan 2003). Fourth, the ARDL allows a simple linear transformation from which a dynamic error correction model can be generated. The error correction method incorporates the short-run dynamics with the long-run equilibrium, preserving longrun information.

The ARDL bounds testing approach includes two stages for assessing the longrun relationship. The first stage is to confirm a long-run association among the variables. If a cointegrating relationship exists, the second stage estimates elasticities in both long and short runs. The estimated error correction term also provides valuable information regarding the short-term adjustment to its long-run equilibrium.

Without any a priori knowledge about the long-run association between our chosen variables, the subsequent unrestricted error correction regressions have been estimated, considering each of the variables in order as a dependent variable, $\Delta \underline{y_{t}}=\left(m_{t}, p_{t}, i e_{t}, u d_{t}\right)$ :

$$
\begin{aligned}
\Delta \underline{y_{t}}= & \alpha_{0}+\alpha_{1} t+\pi_{1} m_{t-1}+\pi_{2} m_{t-1}+\pi_{3} m_{t-1}+\pi_{4} m_{t-1} \\
& +\pi_{5} m_{t-1}+\pi_{6} m_{t-1}+\pi_{7} m_{t-1}+\pi_{8} m_{t-1}+\sum_{i=1}^{n} \gamma_{1, i} \Delta m_{t-i} \\
& +\sum_{i=0}^{n} \gamma_{2, i} \Delta p_{t-i} \sum_{i=0}^{n} \gamma_{3, i} \Delta i e_{t-i} \sum_{i=0}^{n} \gamma_{4, i} \Delta u d_{t-i}+\sum_{i=0}^{n} \gamma_{5, i} \Delta c o_{t-i} \\
& +\sum_{i=0}^{n} \gamma_{6, i} \Delta e n_{t-i}+\sum_{i=0}^{n} \gamma_{7, i} \Delta i m_{t-i}+\sum_{i=0}^{n} \gamma_{8, i} \Delta e d_{t-i}+\varepsilon_{i t}
\end{aligned}
$$

where $m_{t}$ stands for net migration to urban areas, $p_{t}$ is the headcount index of urban poverty, $i e_{t}$ is the urban Gini coefficient, $u d_{t}$ is the urban population as a share of the total population, $c o_{t}$ is the national $\mathrm{CO}_{2}$ emissions, $e n_{t}$ is the national energy consumption, $i m_{t}$ is the infant mortality rate, and $e d_{t}$ is the gross enrollment rate at primary school. The operator $\Delta$ denotes the first difference and all variables are in Naperian logarithms. The parameters $\pi_{j}(j=1, \ldots, 8)$ are the corresponding long-run multipliers in the cointegrating vector of the ARDL model, while the parameters $\gamma_{j i}$ $(j=1, \ldots, 8)$ are the short-run dynamic coefficients in the error correction mechanism.

To capture the autonomous time-related changes, the time trend, $\alpha_{1} t$, is included in the equations. This is confirmed by the figures indicating the variables have trends. A dummy variable for $1991, d_{91}$, coinciding with the start of deregulation in India, is added to the constant term $\alpha_{0}$ to capture any structural breaks. The ARDL model is therefore to be estimated with an unrestricted intercept and an unrestricted trend. 
We test the null hypothesis of no cointegrating relation in Eq. (5.1), $H_{0}: \pi_{i}=\pi_{j}=0$ $\forall i, j=1,2, \ldots, 8 ; i \neq j$, against the alternative hypothesis $H_{0}: \pi_{i} \neq \pi_{j} \neq 0$. The $F$-test is applied to establish whether cointegration occurs among the lagged level of the variables. The null hypothesis is that there is no cointegration between the examined variables, irrespective of whether the variables are purely $I(0)$ or $I(1)$. There are two sets of asymptotic critical values: one all variables are $I(0)$ and the other all variables are $I(1)$ (Pesaran et al. 2001). If the estimated $F$-statistic is greater than the upper-bound critical value, then the null hypothesis of no cointegration will be rejected. If the estimated $F$-statistic is less than the lower-bound critical value, then we will not reject the hypothesis of no cointegration.

\subsection{Johansen Vector Error Correction Model (VECM)}

The Johansen (1995) error correction specification for simultaneous equations is

$$
\Delta y_{t}=\alpha_{0 y}+\alpha_{1 y} t-\prod_{y} y_{t-1}+\sum_{i=1}^{p-1} \Gamma_{i y} \Delta y_{t-i}+\Psi w_{t}+\varepsilon_{t}
$$

where $y_{t}=\left(m_{t}, p_{t}, u d_{t}\right)$ is the vector of endogenous I(1) variables; $w_{t}=\left(i e_{t}, c o_{t}, e n_{t}, i m_{t}, e d_{t}\right)$ is a vector of $I(0)$ deterministic, $i e_{t}$; and $c o_{t}, e n_{t}, i m_{t}$, and $e d_{t}$ are exogenous variables. As for the ARDL approach, the time trend $t$ is included as well as the structural change variable $d_{91}$.

The benefit of this cointegration method is that it is a multiple equation specification and therefore allows a distinction between endogenous and exogenous variables, which is important in our explorations of directions of causation. The maximum eigenvalue, trace, and model selection criteria determine the number of cointegrating associations required to span the data, which describes the uniqueness or otherwise of the long-run cointegrating relationships. Because of the simultaneity specification, the estimation of the parameters has efficiency gains and consistency properties. However, the method requires distinguishing between the $I(1)$ and $I(0)$ variables, as determined in the stationarity testing earlier.

\subsection{State-Level Analysis: Generalized Method of Moments (GMM)}

The problem of estimating this dynamic panel model for state-level data by using ordinary least squares (OLS) leads to a "dynamic panel bias," as the endogeneity problem is unaddressed. The lagged dependent variable $m_{i, t-1}$ is endogenous to the fixed effects $\mu_{i}$, which leads to a "dynamic panel bias" or so-called Nickel bias. In addition, one or more other regressors in the model may be correlated with $\mu_{i}$ and $\nu_{t}$. 
In our analysis, migration and labour market settings are jointly performed (Alecke et al. 2010). The same is true for migration and urban development, migration and poverty/inequality. In these circumstances, the OLS estimates of this baseline model will be unpredictable irrespective of fixed or random effects. First differencing may be one of the options to overcome the problem. However, when an explanatory lagged dependent variable is first differenced, it leads to a correlation among these variables and the differenced error term.

Arellano and Bond (1991) developed the GMM estimator for linear dynamic panel data models that use appropriate instruments to perform with endogeneity of the independent variables. This approach resolves the issue of instrumenting the differenced predetermined endogenous variables with lags in levels. This is also known as differenced GMM (DGMM). Arellano and Bover (1995) show increased efficiency by introducing a system GMM (SGMM) estimator by introducing additional moment conditions. The SGMM procedure shows that in cases where the first differences of the right-hand side. Variables are not correlated with the individual impacts, one can apply the lagged values of the first differences as instruments in levels. This allows the advantage of the better modeling of nonstationary data and good small sample properties, which is relevant to this study.

The expectation of our following baseline models reflects the dynamics and interdependencies among the key variables:

$$
\begin{aligned}
m_{i, t}= & \alpha_{1}+\beta_{1} m_{i, t-1}+\gamma_{1} p_{i, t}+\gamma_{2} i e_{i, t}+\gamma_{3} u d_{i, t}+\gamma_{4} i m_{i, t} \\
& +\gamma_{5} \mathrm{om}_{i, t}+v_{t}+\mu_{i}+\varepsilon_{i, t} \\
p_{i, t}= & \alpha_{1}+\beta_{1} p_{i, t-1}+\gamma_{1} m_{i, t}+\gamma_{2} i e_{i, t}+\gamma_{3} u d_{i, t}+\gamma_{4} i m_{i, t} \\
& +\gamma_{5} o m_{i, t}+v_{t}+\mu_{i}+\varepsilon_{i, t} \\
i e_{i, t}= & \alpha_{1}+\beta_{1} i e_{i, t-1}+\gamma_{1} m_{i, t}+\gamma_{2} p_{i, t}+\gamma_{3} u d_{i, t}+\gamma_{4} i m_{i, t} \\
& +\gamma_{5} o m_{i, t}+v_{t}+\mu_{i}+\varepsilon_{i, t} \\
u d_{i, t}= & \alpha_{1}+\beta_{1} u d_{i, t-1}+\gamma_{1} m_{i, t}+\gamma_{2} p_{i, t}+\gamma_{3} i e_{i, t}+\gamma_{4} i m_{i, t} \\
& +\gamma_{5} \mathrm{om}_{i, t}+v_{t}+\mu_{i}+\varepsilon_{i, t}
\end{aligned}
$$

where $m_{i, t}, p_{i, t}, i e_{i, t}$ and $u d_{i, t}$ are, respectively, defined previously for net migration to urban areas, poverty index, Gini coefficient, and urban population share. The control variables available for the states are restricted to the infant mortality rate, $\mathrm{im}_{i, t}$, and another health measure, the all-others mortality rate, $\operatorname{om}_{i, t}$. The period-specific effects are represented by $\nu_{t}$ and state-specific effects by $\mu_{i}$ while $\varepsilon_{i, t}$ is the error term. In addition to these fixed affects, the lagged variables $m_{i, t-1}, p_{i, t-1}, i e_{i, t-1}$, and, $u d_{i, t-1}$ form the dynamic GMM specification. The parameters to be estimated, $\gamma_{1}, \gamma_{2}$, $\gamma_{3}, \gamma_{4}$, and $\gamma_{5}$, are the elasticities of the interdependencies while the estimates of $\beta_{1}$ measure the degree of inertia in the transmission of shocks.

Migrants will gain by migrating to urban areas. This is mainly due to the urban sector providing higher initial wages relative to the rural sector. One would expect 
that both rural inhabitants and urban migrants gain due to rural to urban migration, but already occupied urban workers may likely experience job losses and wage reductions. If we assume skilled migrants move from rural to urban areas, then the increase or decline of the wages of unskilled migrants depends on the nature of work (e.g. complements or substitutes). If there is a huge wage divergence in the urban sector, this may trigger an income inequality. However, if urban migrants invest in physical capital, this will have implications on urban income and urban income inequality (Lucas 1997).

The association of poverty and inequality with migration is ambiguous. Positive associations between poverty, the Gini coefficient, and net migration indicates that migration will contribute to increased poverty and inequality. This may be due to skilled-biased urban development or high-return investments in new technology by urban migrants.

The greater the in-migration, the greater the urbanization. On the other hand, urbanization motivates more in-migration. The expected positive association will have implications for urban infrastructure, energy use, and the environment. The variables infant mortality rate $i m$ and percentage of urban deaths om (where medical attention is received before death) are used as control variables indicating the health problems associated with urbanization. Their associations with migration are ambiguous.

\subsection{Data}

Migration $(m)$ Data for net urban migration are not available and are estimated using the following equation:

$$
m_{t}=\left(u d_{t}-u d_{t-1}\right)-\frac{\left(u d_{t}+u d_{t-1}\right)}{2} \times\left(b_{t}-d_{t}\right)
$$

where $m_{t}$ is the net urban migration and $u d_{t}$ denotes urban population as a share of total population while $b_{t}$ and $d_{t}$ represent the urban birth and death rates, respectively. All data are obtained from the Planning Commission, Government of India (2014a,b). The national data is estimated for the period 1971-2012, whereas the state-level data is estimated using the same method for the period 2006-2011.

Poverty $(p)$ The proportion of the population with a per capita consumption less than the poverty line is the headcount index (Datt and Ravallion 2009). In India, the urban poverty line is a nutritional norm of 2100 calories per person per day, which is endorsed by the Planning Commission (1993). The poverty line indicates the level of average per capita total expenditure at which this caloric norm was fulfilled. The urban per capita monthly expenditure was considered as Rs 57 at 1973/74 prices (Datt and Ravallion 2009). 
The national headcount index of urban poverty data for 1971-2006 is collected from Datt and Ravallion (2010). The state-level headcount index of urban poverty data for the years 2006, 2009, and 2011 is obtained from the Planning Commission (2014a, b).

Inequality (ie) The Gini coefficient is used as a measure of inequality. National urban Gini coefficients for the period 1971-2012 are taken from the World Income Inequality Database of UNU-WIDER and the World Bank (2014). The state-level Gini coefficient data for 2006-2011 are obtained from the Planning Commission, Government of India (2014a, b). Both are based on the NSS distribution of household consumption data.

Urbanization $(u d)$ The urban population share of the total population is an indicator of urbanization. The national-level data from 1971 to 2012 come from the World Development Indicator (WDI), World Bank (2014) and the state-level data from the Planning Commission (2014a, b).

Control Variables National $\mathrm{CO}_{2}$ emissions, ( $\mathrm{co}$ ) (thousand metric tons of carbon, 1971-2012) and energy consumption, (en) (kg of oil equivalent, 1971-2011) are obtained from the WDI, World Bank (2014). National- and state-level data for the urban infant mortality rate $(\mathrm{im})$, national data for the gross enrollment ratio in primary school $(e d)$, and state-level data for the all-others mortality rate $(\mathrm{om})$ (per cent of deaths in urban areas where medical attention was received before death) are from the Planning Commission, Government of India (2014a,b). All data are in Naperian logs.

\section{Empirical Results}

The dynamic, long-run cointegrating analysis will use national-level data from 1971 to 2012 and focus on urban migration, urban poverty (measured by the expenditurebased urban headcount ratio), and inequality. The spatial estimates for 16 Indian states using SGMM for the shorter period from 2006 to 2011 reinforce the time series results. The results will also show additional feedback effects that are occurring between urban poverty and inequality, demonstrating an upward/downward spiral.

\subsection{Cointegration}

For the ARDL estimation, the $F$-statistic indicating the null hypothesis of no cointegration among the variables is rejected when net urban migration, inequality, poverty, and urban population are the respective dependent variables. The computed $F$-statistic for these four variables are 22.04, 12.53, 8.02, and 25.00, respectively, greater than the upper-bound critical value at the 5\% significance level. This result suggests that there exists a long-run association between net urban migration, $m$, and the variables $p, i e, u d, c o, e n, i m$, and $e d$. This is also true for inequality ie, 
poverty $p$ and urban population share $u d$ being the dependent variables. Given that the test results suggest that a long-run cointegrating association exists between the variables, the next step is to estimate the long-run and short-run coefficients. The maximum lag set for error correction is three.

With net urban migration $m$ as the dependent variable, Table 5.2 indicates a significant, positive relationship between net urban migration $m$ and Gini coefficient ie as well as poverty $p$ but a negative relationship with urban population share $u d$. A $1 \%$ increase in the Gini coefficient increases migration by $0.71 \%$ in the long run, which is significant at the 5\% level, indicating an increase in urban inequality and thus increased migration to urban areas. As explained earlier, this may reflect a skill and technology bias in urban migration. Increasing inequality in the form of an emerging middle class could also act as a signal to migrants. The coefficient of headcount urban poverty index $p$ is also positive in the long run, showing that $1 \%$ rise in the proportion of the population with a standard of living below the poverty line will increase migration to urban areas by $0.5 \%$, which is significant at the a $1 \%$ level. This result may reflect increasing rural poverty relative to urban poverty acting as a push effect from agriculture.

The negative coefficient of urban population share $u d$ indicates that a $1 \%$ increase in urban population will lead to a $3.42 \%$ decrease in in-migration to urban areas in the long run at the $1 \%$ level of significance. Carbon dioxide emissions co affect urban migration negatively in the long run-a $1 \%$ increase in co leads to a $1 \%$ decrease in in-migration $m$ to urban areas, possibly indicating that cities with low air pollution are the preferred destination of migrants.

Lastly, both the national infant mortality rate im and primary school enrollment $e d$ have positive relationships with urban migration in the long run. Specifically, a $1 \%$ increase in $\mathrm{im}$ and $e d$ leads to an increase in the long-run urban migration $m$ of around $2.80 \%$ and $0.64 \%$, respectively, both significant at the $1 \%$ level.

The error correction is significant at the $1 \%$ level with the expected negative sign. The estimate of -1.36 represents a rapid within year adjustment of migration to its stable long-run relationship following a shock, with some overcorrection in the next year.

Table 5.2 indicates that poverty $p$ is positively affected by net urban migration $m$. This is an important finding: a $1 \%$ increase in-migration $m$ increases poverty $p$ by $0.83 \%$ in the long run, significant at the $1 \%$ level. Poverty also increases with $\mathrm{CO}_{2}$ emissions. There is a two-way causation; the previous section found that poverty $p$ causes net urban migration $m$. A $1 \%$ increase in $c o$ increases poverty $p$ by a large $2.55 \%$, at the $1 \%$ significance level. But a $1 \%$ increase in im decreases poverty $p$ by a large $3.31 \%$ at the $1 \%$ significance level.

Again, as with the previous two models, the significant error correction of -1.35 indicates a rapid within-period overshooting adjustment to the long-run steady state.

For inequality ie as the dependent variable, Table 5.2 indicates only one significant, long-run, positive relationship with the urban population share of total population $u d$. A $1 \%$ increase in $u d$ increases ie by $3.13 \%$ in the long run, significant at the $1 \%$ level. This indicates that an increase in urban population leads to inequality in urban areas. The structural break dummy of 1991 coinciding with India's deregulation was significant at the $5 \%$ level. The short-term error correction also shows significant overshooting. 


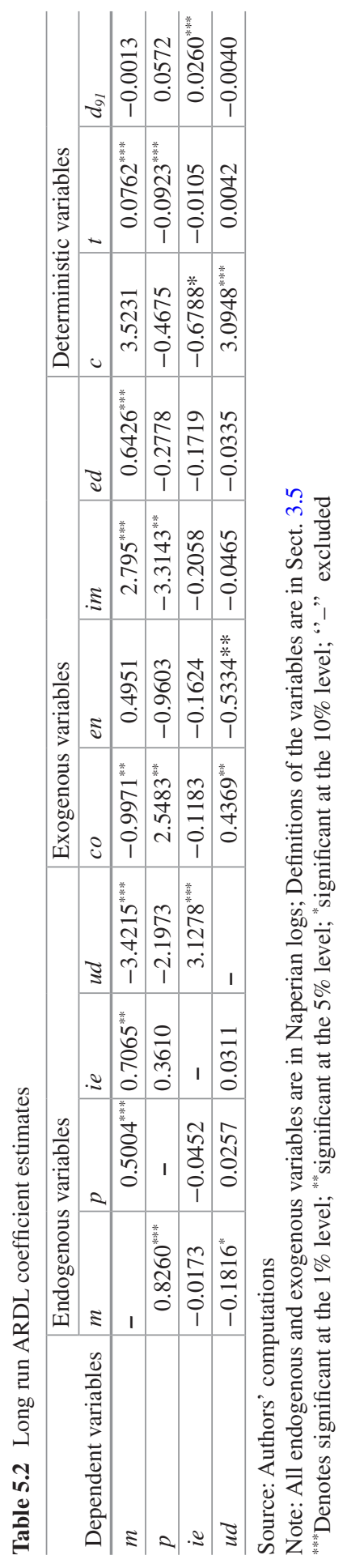


Table 5.2 shows that $\mathrm{CO}_{2}$ emissions and energy consumption significantly affect urbanization (urban population as a percentage of total population) positively and negatively, respectively. A $1 \%$ increase in co increases urbanization $u d$ by $0.44 \%$ at the $1 \%$ significance level, while a $1 \%$ increase in en decreases $u d$ by $0.53 \%$ at the $1 \%$ significance level.

The diagnostic tests show that the model passes majority of the tests in relation to serial correlation, functional form, normality, and heteroscedasticity. The $R^{2}$ is high for all the ARDL models. This shows that the overall goodness of fit for the model as a whole. Lastly, the Durbin-Watson statistic for all the models is close to or more than two.

The important conclusion here is that there are positive feedback effects between urban migration and urban poverty and between urban poverty and urban migration. These positive feedback effects are unexpected, given the increasing migration and decreasing poverty measures shown in Figs. 5.1, 5.2, and 5.3. A closer analysis of the ARDL results shows that the time trend term for both equations is significant at the $1 \%$ level. The trend for the migration equation is positive at $7.6 \%$, and the trend for the poverty equation is falling at $-9.2 \%$. The important, estimated, long-run positive relationships between urban migration and poverty are over and above these trends. However, this relationship may be due to the endogeneity effects providing inconsistent estimates. This will now be explored.

The Johansen estimation accounts for endogeneity that requires the distinction between $I(1)$ and $I(0)$ variables. Accordingly, as shown in Table 5.3, the stationary inequality variable ie (which accords with its constancy in Figs. 5.2 and 5.3) is classified as a deterministic, non-endogenous variable. There is therefore no column for it in the endogenous section, which is consistent with the ARDL findings of the variable having no significant effects on the $I(1)$ endogenous variables. Since it cannot be included in the long-run cointegrating vector, there is also no equation or row with it as the long-run-dependent variable.

The VAR model selection criteria set the optimum lag as one. The cointegration estimation with unrestricted intercept and trend derived the eigenvalues of 0.947 , 0.504 , and 0.369 . The maximum eigenvalue criterion selected a rank of one, reflecting the very high first eigenvalue, while the trace and model selection criteria indicated a possible rank of two (the maximum of three was not considered because of the degrees of freedom constraint). The rank of one was selected, and the cointegrating vector was estimated as

$$
\{m=1.773, p=-0.800, u d=-5.073, c o=-1.291, \text { en }=2.766, \mathrm{im}=0.523, \text { ed }=0.614\} .
$$

Imposing the required normalizing identifying restriction for each of the three equations gives the elasticity estimates shown in Table 5.3. The results are similar to the ARDL findings with some changes to coefficient sizes.

The positive relationships between urban migration and urban poverty remain, with the elasticity for poverty affecting migration, which falls only slightly from 0.50 to 0.45 , still significant at the $1 \%$ level. However, the inelastic effect of migration on poverty increases from 0.83 to an elastic 2.22 , again significant at the $1 \%$ level. Remember that the Johansen procedure takes into account the endogeneity of 


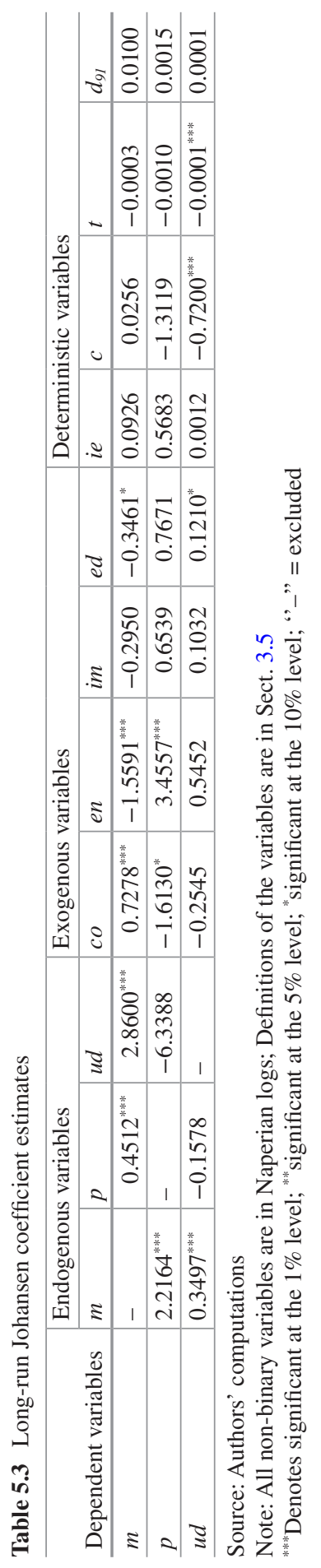


these variables and provides robust evidence with the ARDL findings of this positive relationship. While the error corrections are not significant, the diagnostic tests are satisfactory but with the possibility of a serial correlation in the poverty variable. Whether this is sufficient to question the positive, identified long-run relationship can be further explored with the spatial estimation using data for the Indian states. The panel SGMM estimation will add another dimension to this temporal analysis and will give an indication of robustness or otherwise.

\subsection{SGMM Panel}

We start with estimating coefficients using a fixed effect model (FE), and the results are reported in Table 5.4. The results span 16 states and 6 years, 2006-2011. Using urban migration as a dependent variable, a $1 \%$ rise in urban poverty in the states increases urban migration by $0.59 \%$ at the $5 \%$ significance level. The reverse effect is also positive but small, with a $1 \%$ rise in urban migration increasing urban poverty by $0.08 \%$ at the $5 \%$ significance level.

There is an interesting positive feedback effect occurring between urban poverty and urban inequality. The elasticities are significant at the $1 \%$ level, with values 0.12 for poverty affecting inequality and 1.99 for inequality affecting poverty. The urban inequality increases net migration by $2.78 \%$.

This method ignores the likely endogeneity problems with our main variables and excludes the use of a lagged dependent variable. Theory suggests that the variables are endogenous, and this brings suspicion to the results of fixed effects. To overcome this problem, second lagged variables are used as instruments, as they are exogenous in both the dynamic and system GMM procedures (DGMM and SGMM). The SGMM approach also incorporates state effects separately as instruments, whereas DGMM automatically differences out the state effect, as it is a fixed effect.

The SGMM method considers migration, poverty, inequality, and urban population to be endogenous variables. All other variables are treated as exogenous. The Sargan test fails to reject the null, indicating the instruments used in the regressions are appropriate.

The AR(1) test looks at the correlation between the differenced residual between time $t$ and time $t-1$. This is expected to be correlated because, by definition, it is the differenced term (both terms share the same lagged residual term). However, we would not expect any correlation between time $t$ and time $t-k$ for $k$ greater than unity because the residuals should not be correlated. The AR test makes more intuitive sense when using DGMM, which differences the equation, whereas SGMM uses alternative methods, and therefore the AR(1) test is not as applicable.

The Sargan test fails to reject the null in general when applying only the second lag of endogenous variables as instruments (except poverty as a dependent variable). The reason why the second lag is used is because of the limited observations, and it leads to overidentifying restrictions being valid. The $\operatorname{AR}(2)$ test performs poorly if either migration or inequality is the dependent variable.

We therefore prefer the SGMM procedure and used a one-step SGMM that included the state effects. The results are presented in Table 5.5. A 1\% rise in poverty 


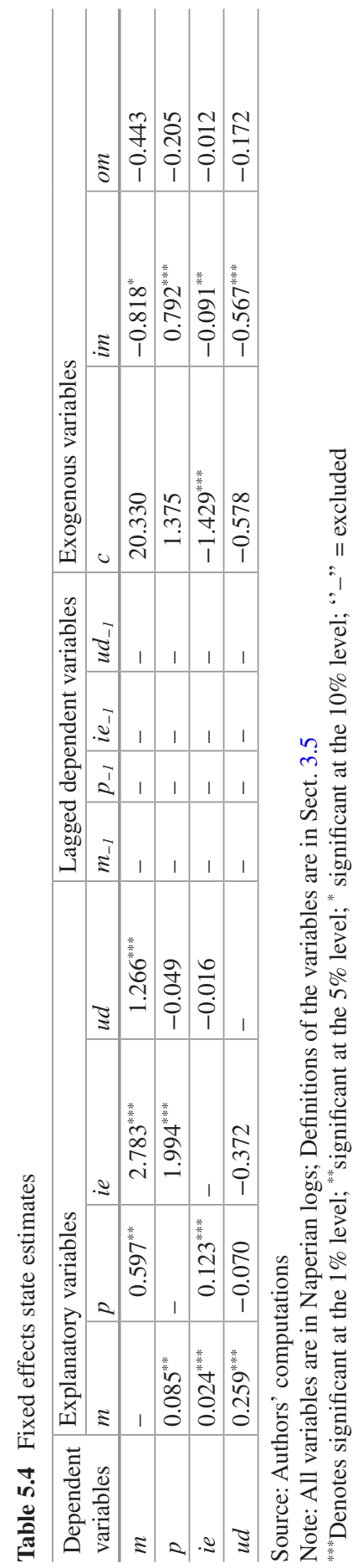




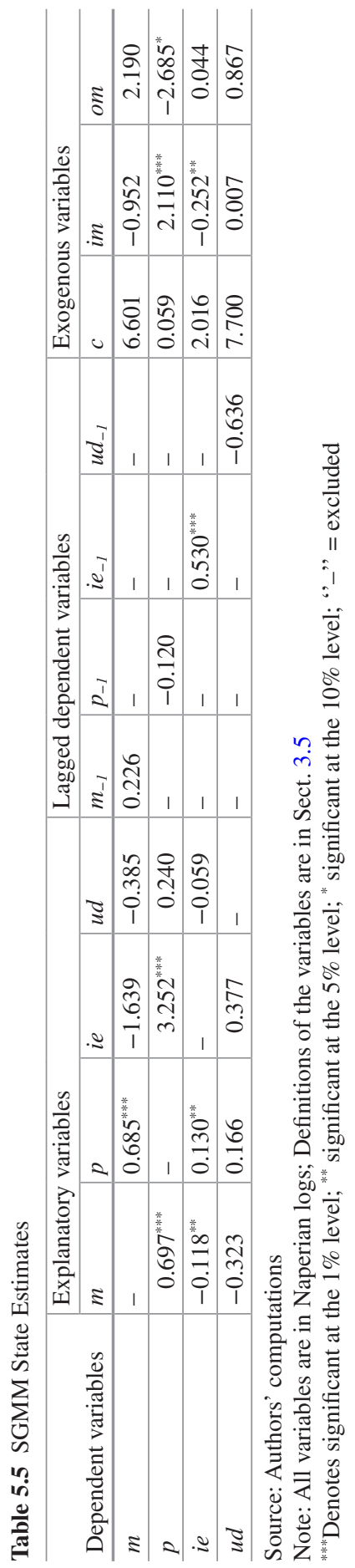


will increase migration by $0.68 \%$, whereas a $1 \%$ rise in migration will increase poverty by $0.69 \%$. Both of these elasticities are at the $1 \%$ significance level. Allowing for endogeneity in estimation has increased the estimated elasticity from the fixed effects value of 0.08 for migration affecting poverty to the SGMM value of 0.70 .

Using poverty as a dependent variable, a $1 \%$ rise in inequality will increase poverty by $3.25 \%$. Using inequality as a dependent variable, a $1 \%$ increase in poverty will increase inequality by $0.13 \%$. The same increase in net migration will decrease inequality by $0.12 \%$. Infant mortality increases poverty with an elasticity of 2.11 . Lagged inequality has a positive and significant impact in this model by affecting the current inequality with an elasticity of 0.53 .

We do estimate state and time impacts in all four dependent variables. The majority of the coefficients are not significant, and therefore they are not reported here. Agricultural-based Haryana (-15.8) and the poor state of Orissa (-10.4) show negative state coefficients when we use poverty as a dependent variable. Chhattisgarh attracts positive net migration and shows positive and significant impacts on inequality $(+1.15)$ as the dependent variable. The time variable shows lower inequality in the earlier years, 2007 and 2008, and increased urban growth in 2010.

\section{Conclusions}

In order to show the interdependencies, the dynamic long-run cointegrating analysis and the spatial Indian state-level panel analysis using SGMM have been used. There are significant long-run bidirectional linkages between urban poverty and urbanization.

The two-way effects are positive with urbanization, $m$ (increasing urban population due to migration and urban sprawl) increasing urban headcount poverty, $p$. The elasticities range from 2.2 to 0.3 , with the larger elastic response identified and estimated concurrently with all the other possible relationships while the inelastic estimate comes from estimating the individual urbanization-poverty pairing in isolation. These relationships are determined net of the longer term drifts for these variables and so demonstrate the linkages based on variations in the annual data over and above the trend effects. Both estimation procedures show a feedback where urban poverty is linked to urbanization with a mid-range inelastic value of around 0.5. This may reflect the long-run process whereby rural areas develop into urban areas and the previously defined rural poor are reclassified as new urban poor. These statistically significant estimates clearly show that increasing urban populations contribute to urban poverty in India.

There is also an interesting bidirectional feedback between relative urban size and urbanization. The major direction of influence, with an elasticity of nearly 3 , runs from relative urban size to urbanization. This is consistent with agglomeration, 
in terms of urban growth being concentrated in larger cities, which, in turn, feeds through to increasing urban poverty. This is consistent with the outcomes of Ravallion et al. (2007) who provide evidence that urbanization facilitated a fall in absolute poverty, in general, but did little for urban poverty. They found that over the 1993-2002 period, the estimate of the "\$1 a day" poor reduced by 150 million in rural areas but increased by 50 million in urban areas. In contrast, one can find there is no indication of any significant long-run linkages between urban inequality ie, and urban poverty $p$ nor with any of the other variables.

The linkages differ for the spatial estimations for India over the later and shorter time period. Urban inequality $i e$ is very much part of the story, having bidirectional links with urban poverty $p$ across the 16 Indian states. Urban inequality adversely affects urban poverty with an elastic estimate of over 3, dominating the reverse inelastic measure for poverty to inequality. The estimated bidirectional elasticities between poverty and urbanization for the Indian states remain and are comparable with the intertemporal long-run estimates. Urban poverty is therefore central to the development of the Indian states, having links with both urbanization and inequality. They are significant at the $1 \%$ or $5 \%$ levels, whereas the longer-run demographic influences via urban size are not significant for the 16 states over this shorter and later time period.

Based on this evidence, urban poverty and urban inequality should therefore not be considered independent and separable problems, particularly with the identified further linkages with migrant expenditure and the process of urbanization. This interdependence requires formulating appropriately encompassing and consistent urban development strategies. Policies therefore need to take into account possible policy-induced linkages when attempting to reduce urban inequality and urban poverty.

\section{References}

Alecke, B., Mitze, T., \& Untiedt, G. (2010). Internal migration, regional labour market dynamics and implications for German east-west disparities: Results from a panel VAR. Review of Regional Research, 30(2), 159-189.

Arellano, M., \& Bond, S. (1991). Some tests of specification for panel data: Monte Carlo evidence and an application to employment equations. Review of Economic Studies, 58(2), 277-297.

Arellano, M., \& Bover, O. (1995). Another look at the instrumental variable estimation of errorcomponents models. Journal of Econometrics, 68(1), 29-51.

Bandyopadhyay, S. (2011). Rich states, poor states: Convergence and polarization in India. Scottish Journal of Political Economy, 58(3), 414-430.

Cali, M., \& Menon, C. (2009). Does urbanization affect rural poverty? Evidence from Indian Districts. Discussion Paper 14, Special Economics Research Centre, London School of Economics.

Carlsen, F. (2000). Testing equilibrium models of regional development. Scottish Journal of Political Economy, 47(1), 1-24. 
Cashin, P., \& Sahay, R. (1996). Internal migration, center-state grants, and economic growth in the states of India. IMF Staff Papers, 43(1), 123-171.

Castaldo, A., Deshingkar, P., \& McKay, A. (2012). Internal migration, remittances and poverty: Evidence from Ghana and India. Working Paper 12, University of Sussex.

Datt, G., \& Ravallion, M. (2009). Has India's economic growth become more pro-poor in the wake of economic reforms?. Policy Research Working Paper 5103, World Bank.

Datt, G., \& Ravallion, M. (2010). Shining for the poor too? Economic \& Political Weekly, 13(7), 55-60.

Datta, P. (2006). Urbanization in India, population studies unit Indian. Kolkata: Statistical Institute.

Deshingkar, P. (2010). Migration, remote rural areas and chronic poverty in India. ODI Working Paper 323, London: Chronic Poverty Research Centre.

Hugo, G. (2014). 'Migration, Urbanization and poverty in Asia: A Demographic Response', invited paper presented to the ADB workshop on Internal Migration, Urban Development, Poverty and Inequality in Asia: Sustainable Strategies and Coordinated Policies to Improve Well-being, 5-7 November, City Angkor Hotel, Siem Reap, Cambodia.

Jack, M. (2006). Urbanization, sustainable growth and poverty reduction in Asia. IDS Bulletin, $37(3), 101-113$.

Johansen, S. (1995). Likelihood based inference on cointegration in the vector autoregressive model. Oxford: Oxford University Press.

Kundu, A., \& P. C. Mohanan (2009). "Employment and inequality outcomes in India", unpublished working paper, New Delhi: Jawaharlal Nehru University/Indian Statistical Service.

Lucas, R. E. B. (1997). Internal migration in developing countries. In M. R. Rosenzweig \& O. Stark (Eds.), Handbook of population and family economics. Amsterdam: Elsevier Science B. V.

Ministry of Statistics. (2010). Migration in India 2007-08, NSS Report No. 533, National Sample Survey Office and Programme Implementation. Government of India.

Ministry of Urban Development. (2011). "Report on Indian Urban Infrastructure and Services. Government of India, New Delhi. http://icrier.org/pdf/FinalReport-hpec.pdf

Narayan, P., \& Narayan, S. (2003). Savings behaviour in Fiji: An empirical assessment using the ARDL approach to cointegration. Discussion Papers, 02/03, Melbourne: Monash University.

Pesaran, M., \& Pesaran, B. (1997). Working with microfit 4: Interactive econometric analysis. Oxford: Oxford University Press.

Pesaran, M., \& Pesaran, B. (2009). Working with microfit 5: Interactive econometric analysis. Oxford: Oxford University Press.

Pesaran, M. H., \& Shin, Y. (1998). An autoregressive distributed lag modelling approach to cointegration analysis. In S. Storm, A. Holly, \& P. Diamond (Eds.), Econometrics and economic theory in the 20 th century: The ranger Frisch centennial symposium. Cambridge: Cambridge University Press.

Pesaran, M. H., Shin, Y., \& Smith, R. P. (2001). Bounds testing approaches to the analysis of level relationships. Journal of Applied Econometrics, 16(3), 289-326.

Planning Commissions. (1993). Report of the expert group on estimation of proportion and number of poor. New Delhi: Government of India.

Planning Commission. (2012). Poverty Estimates for 2009-10, Government of India, New Delhi, http://pib.nic.in/newsite/PrintRelease.aspx?relid=81151, Accessed at 14 Dec 2017.

Planning Commission. (2014a). Data book for using Deputy Chairman, Planning Commission. New Delhi: Government of India.

Planning Commission. (2014b). "Data and Statistics, Government of India", New Delhi, http:// planningcommission.nic.in/data/datatable/index.php?data=datatab,accessed, Accessed at 9 Oct 2014.

Ravallion, M., Chen, S., \& P. Sangraula (2007). New evidence on the urbanization of global poverty. World Bank Policy Research Working Paper 4199, World Bank, Washington, DC, April.

Satterthwaite, D. (1997). Urban poverty: Reconsidering its scale and nature. IDS Bulletin, 28(2), 9-23. 
UN DESA. (2014). Population division, world urbanization prospects: The 2014 Revision, CD-ROM Edition, United Nations, Geneva.

World Bank. (2015a). Development research group, Washington, http://iresearch.worldbank.org/ PovcalNet/index.htm?0. Last Accessed 5 June 2015.

World Bank. (2015b). World Development Indicator (WDI). Geneva: World Bank.

World Income Inequality Database of UNU-WIDER (WIID). (2014). World Bank, Geneva.

The views expressed in this publication are those of the authors and do not necessarily reflect the views and policies of the Asian Development Bank (ADB) or its Board of Governors or the governments they represent.

ADB does not guarantee the accuracy of the data included in this publication and accepts no responsibility for any consequence of their use. The mention of specific companies or products of manufacturers does not imply that they are endorsed or recommended by ADB in preference to others of a similar nature that are not mentioned.

By making any designation of or reference to a particular territory or geographic area, or by using the term "country" in this document, $\mathrm{ADB}$ does not intend to make any judgments as to the legal or other status of any territory or area.

Open Access This work is available under the Creative Commons Attribution-NonCommercial 3.0 IGO license (CC BY-NC 3.0 IGO) http://creativecommons.org/licenses/by-nc/3.0/igo/. By using the content of this publication, you agree to be bound by the terms of this license. For attribution and permissions, please read the provisions and terms of use at https://www.adb.org/ terms-use\#openaccess.

This CC license does not apply to non-ADB copyright materials in this publication. If the material is attributed to another source, please contact the copyright owner or publisher of that source for permission to reproduce it. ADB cannot be held liable for any claims that arise as a result of your use of the material.

Please contact pubsmarketing@adb.org if you have questions or comments with respect to content, or if you wish to obtain copyright permission for your intended use that does not fall within these terms, or for permission to use the ADB logo.

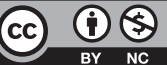

